\title{
Effect of Socio-Economic Status on Motor Fitness Parameters
}

\author{
Yuvraj Singh Ranawat ${ }^{1 *}$, Dr. Um Singh Rathore ${ }^{2}$
}

\section{ABSTRACT}

Despite being challenged in recent years, the hypothesis that individuals of higher socioeconomic status (SES) are more physically active than their lower SES counterparts is generally considered a fact. The present paper is to study the effect of socio-economic status on motor fitness of university level players. The sample consists of 450 university level players from three universities of Udaipur. The Socio-economic scale by Kuppuswami and Aapher fitness test is used as tools of the study. The one way ANOVA was used and results indicate that there is significant effect of socio-economic status on motor fitness of university level players.

\section{Keywords: Socio-Economic Status, Motor Fitness}

Sports and physical education play an important role human resource development. Games and other outdoor activities properly planned and executed, promote social harmony, discipline and increased productivity. These activities develop in student's right attitudes and values and help them grow into balanced, integrated and healthy citizens. Participation in physical activities and sports is a fundamental right of every citizen. Physical education and sports are essential elements of educational processes which promote among the participants health, physical fitness and quality of life. Fitness is an individual matter. It implies the ability of each person to live more effectively with his potentiality of function and it depends upon the physical, mental, social, spiritual and emotional components, which are related to each other and are mutually interdependent. Fitness in broad terms denoting dynamic qualities which allow one to satisfy his own needs and at the same time contribute to the common welfare of one's society. The term physical fitness means more than muscular strength and stamina. It implies efficient performance in exercise or work and a reasonable means of skill in the performance of selected physical activities. The physical fitness is one of the facts of a person's all round harmonious development. Physical fitness is the cultural phenomenon of great complexity and magnitude, which is historically preconditioned level of health and comprehensive development of a person. The place of physical fitness in any society reflects something of that society's characteristics. Today almost every country in the world gives importance to development of sports in order to improve the nation's health and for the well-being of the future generation. Physical fitness is generally judge by the performance and this performance is based on composite of many factors such as self-

\footnotetext{
${ }^{1}$ Research Scholar, Department of Physical Education, Mohanlal Sukhadia University, Udaipur, India

${ }^{2}$ Senior Lecturer \& Head, B.N.P.G. College, Udaipur, India

*Responding Author
}

Received: August 01, 2017; Revision Received: September 27, 2017; Accepted: September 30, 2017

(C) 2016 Ranawat, Y.S \& Rathore, U.S; licensee IJIP. This is an Open Access Research distributed under the terms of the Creative Commons Attribution License (http://creativecommons.org/licenses/by/2.0), which permits unrestricted use, distribution, and reproduction in any Medium, provided the original work is properly cited. 
confidence, motivation, aggression, anxiety, socioeconomic status, locus of control etc. these factors have generally been considered being most commonly mentioned components of physical fitness. Higher level of physical fitness is fundamental to success in all type of sports and games. To become a top level performer in any sports and games, it is essential that he should have a sound fit body.

The various studies have been made by different researches on the influence of socioeconomic status on the physical fitness and sports performance.

More recently, however, several papers have emerged questioning this relationship, among them the reviews by Gidlow, Johnston, Crone, Ellis, and James; Beenackers, Kamphuis, Giskes, Brug, Kunst, Burdorf and Lenthe and Stalsberg and Pedersen. Beenackers et al., in fact, found that in studies reporting occupational physical activity, low-SES groups came out as more active, whereas the results were similar across SES groups for active transport. The only domain in clear favor of high-SES groups was leisure-time physical activity. For total physical activity, the picture was mixed, with about the same number of studies reporting each way. Gidlow et al., although reporting a clear effect of SES when comparing the most extreme (highest and lowest) SES groups, reported relatively mixed results for the remainder of the data. Gidlow et al. discussed problems with the operationalization of the SES variable but reported that education was most commonly used and seemed to produce the most stable relationships. Stalsberg and Pedersen identified similar methodological problems with both variables (physical activity and SES) as mentioned above and revealed also that more than $40 \%$ of studies on adolescents had found no differences in physical activity across SES groups. A few even reported opposite results with the low-SES group as more active.

\section{Objective}

To study the effect of socio-economic on physical fitness of university level players.

\section{Hypothesis}

There is no significant effect of socio-economic on physical fitness of university level players.

\section{Sample}

A sample of 450 university level players between age group of 18-27 years was randomly selected through survey method from three universities namely from Mohanlal Sukhadia University, Udaipur Janaradan Rai Nagar University, Udaipur Maharana Pratap University of Agriculture and Technology, Udaipur. The male players were selected randomly from all the three universities. Only those players were selected who had participated at university level tournaments either in individual field sport of team sport event.

\section{Inclusion Criteria}

To select the subject following criteria of inclusion were fixed by the researcher:

i. Subject must have represented at university level tournament.

ii. Subject must have participated as a member of the college team in field games.

iii. Subject should be of male gender.

iv. Subject's age should be 18 years to 27 years 


\section{Tools of the study}

\section{Socio-Economic Status Scale}

A standardized tool made by Kuppuswami modified version (2018) was used for the study. It is important tool in hospital and community based research in Indian situation. It includes, education of head of family, occupation of head of family and income per month from all sources. The present scale classifies the study populations into high, middle and low Socioeconomic status. It yields a score of 3-29.

The SES scale test originally developed by Kuppuswami was used. The modified version in 2018 by Kuppuswamy is used for the present research work. The test is a standardized tool for measuring socio-economic status of individuals. The test possess high reliability and validity.

\section{Motor Fitness Components}

For measuring motor fitness the AAPHER test was used The following motor fitness components were selected:

Sit-Ups (Legs Strength)

Shuttle Run (Agility)

Standing Long Jump (Explosive Strength/Power)

50 Yard Dash (Speed)

Pull-ups (Hands Strength)

600 Yard Run and Walk (Endurance)

\section{Details of Motor Fitness Tests (Aapher) \\ Sit ups \\ Tools}

Hard floor and stopwatch.

\section{Description}

The individual expected to lie on his back with his bowed knees, it ought to be contemplated that the feet on the floor and impact points ought not in excess of 12 crawls from the hindquarters. It ought to be likewise dealt with the edge at the knees ought not in excess of 90 degrees. The individual needs to put his hands on the rear of his neck with fingers shut and elbows set soundly on the floor. His feet ought to be held by the scorer to keep them in contact with the surface. The individual fixes his muscular strength and brings his head and elbows forward as he twists up, at long last contacting elbows to knees. This activity establishes one sit-up. The student re-visitations of the beginning situation with his elbows on a superficial level before he sits up once more. The clock gives the sign "prepared go," and the sit-up execution is begun "go." Performance is halted on "stop." The quantity of effectively executed sit-ups acted in 60 seconds will be the score.

\section{Rules}

- Just a single preliminary will be permitted except if the instructor accepts the understudy has not had a reasonable chance to perform.

- No resting is allowed between sit-ups.

- No sit-ups will be included in which the student doesn't (a) keep the fingers fastened behind the neck; (b) present the two elbows in beginning to sit up without pushing off the floor with an elbow; or (c) re-visitation of beginning situation, with elbows level on a superficial level, before sitting up once more. 


\section{Effect of Socio-Economic Status on Motor Fitness Parameters}

\section{Scoring}

Record the quantity of effectively executed sit-ups the student can do in 60 seconds. A foul invalidates the mean that sit-up. The watch is begun "go" and halted on "stop"

\section{Shuttle Run}

\section{Tool}

Two wooden block having size of 2 inches $\mathrm{x} 2$ inches $\mathrm{x} 4$ inches with a stopwatch.

Players should wear sports shows.

\section{Description}

Two equal lines are set apart on the floor 30 feet separated. The width of a guideline volleyball court fills in as an appropriate region. Spot the squares of wood behind one of the lines. The student begins from behind the other line. On the sign "Prepared? Go!" the student hurries to the squares, gets one, runs back to the beginning line, and places the square behind the line; he at that point runs back and gets the subsequent square, which he conveys back over the beginning line. On the off chance that the scorer has two stopwatches or one with a brief moment clock, it is desirable over have two students running simultaneously. To kill the need of restoring the squares after each race, start the races on the other hand, first from behind one line and afterward from behind the other.

Rules

- Permit two preliminaries with some rest between.

Scoring

Record the hour of the better of the two preliminaries to the closest 10th of a second.

\section{Standing Long Jump}

\section{Tools}

Jumping pit and measurement tape.

\section{Description}

Understudy remains with the feet a few inches separated and the toes simply behind the departure line. Preliminary to hopping, the student swings the arms in reverse and curves the knees. The bounce is cultivated by all the while broadening the knees and swinging forward the arms.

\section{Rules}

- Permit three preliminaries.

- Measure from the departure line to the heel or other aspect of the body that contacts the floor closest the departure line.

- At the point when the test is given inside, it is helpful to tape the measuring tape to the floor at right edges to the departure line and have the students hop along the tape. The scorer stands aside and watches the imprint to the closest inch.

\section{Scoring}

Record the best of the three preliminaries in feet and creeps to the closest inch and converted in $\mathrm{cm}$ through conversion formula.

\section{0 yards dash}

\section{Tools}

Split second timer.

\section{Description}

It is desirable over direct this test to two students all at once. Have both take positions behind the beginning line. The starter will utilize the orders "Are you prepared?" and "Go!" The last 
will be joined by a descending compass of the starter's arm to give a visual sign to the clock, who remains toward the end goal.

\section{Rules}

- The score is the measure of time between the starter's sign and the moment the Scoring understudy crosses the end goal.

Record in seconds to the closest 10th of a second.

\section{Pull ups}

\section{Tools}

A doorway gym bar.

\section{Description}

The bar should be high enough so that the pupil can hang with his arms and legs fully extended and his feet free of the floor. He should use the overhand grasp. After assuming the hanging position, the pupil raises his body by his arms until his chin can be placed over the bar and then lowers his body to a full hang as in the starting position. The exercise is repeated as many times as possible.

\section{Rules}

- Allow one trial unless it is obvious that the pupil has not had a fair chance.

- The body must not swing during the execution of the movement. The pull must in no way be a snap movement. If the pupil starts swinging, check this by holding your extended arm across the front of the thighs.

\section{Scoring}

- The knees must not be raised and kicking of the legs is not permitted.

Record the number of completed pull-ups to the nearest whole number.

\section{0 yard walk and run}

\section{Tools}

Running Track and stopwatch.

\section{Description}

Pupil uses a standing start. At the signal "Ready? Go!" the pupil starts running the 600 -yard distance. The running may be interspersed with walking. It is possible to have a dozen pupils run at one time by having the pupils pair off before the start of the event. Then each pupil listens for and remembers his partner's time as the latter crosses the finish. The timer merely calls out the times as the pupils cross the finish.

\section{Rules}

- Walking is permitted, but the object is to cover the distance in the shortest possible time.

\section{Scoring}

Record in minutes and seconds.

\section{Method of Data Collection}

First of all on the basis of Socio-economic the sample was categorized into five levels. To gather the information the analyst visited different universities and actually met all the understudies. The researcher clarified plainly in Hindi language about the motivation behind the investigation alongside the technique of the test. Time taken to finish the undertaking by every one of the subject was 3-4 minutes. A large portion of the subjects reacted in certain way with incredible excitement and straightforwardness. All subjects were amassed and a 


\section{Effect of Socio-Economic Status on Motor Fitness Parameters}

concise portrayal was given about the reason and prerequisite of testing methods of the investigation to cause them to comprehend about what they are really needed to do during the analysis or the examination. All subjects concurred deliberately to coordinate in the testing technique which was to be disclosed to them.

\section{Statistical Analysis}

To analyse the data, various statistical methods was applied ANOVA. The level of significance was set at 0.05 . All the statistical calculations were done through SPSS (version 21.0).

\section{RESULTS AND DISCUSSION}

The following table shows the effect of socio-economic status on Motor Fitness Parameters.

\section{Table 1}

Effect of Socio-economic status on Motor Fitness Parameters

\begin{tabular}{|c|c|c|c|c|c|c|}
\hline 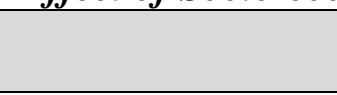 & & $\begin{array}{l}\text { Sum of } \\
\text { Squares }\end{array}$ & df & $\begin{array}{l}\text { Mean } \\
\text { Square }\end{array}$ & $\mathbf{F}$ & Sig. \\
\hline \multirow{3}{*}{$\begin{array}{l}\text { Sit-Ups } \\
\text { (Legs Strength) }\end{array}$} & Between Groups & 3790.279 & 4 & 947.570 & \multirow[t]{3}{*}{978.484} & \multirow[t]{3}{*}{0.000} \\
\hline & Within Groups & 430.941 & 445 & 0.968 & & \\
\hline & Total & 4221.220 & 449 & & & \\
\hline \multirow{3}{*}{$\begin{array}{l}\text { Shuttle Run } \\
\text { (Agility) }\end{array}$} & Between Groups & 50.886 & 4 & 12.721 & \multirow[t]{3}{*}{42.980} & \multirow[t]{3}{*}{0.000} \\
\hline & Within Groups & 131.715 & 445 & 0.296 & & \\
\hline & Total & 182.601 & 449 & & & \\
\hline \multirow{3}{*}{$\begin{array}{l}\text { Standing Long Jump } \\
\text { (Explosive } \\
\text { Strength/Power) }\end{array}$} & Between Groups & 2.147 & 4 & 0.537 & \multirow[t]{3}{*}{50.439} & \multirow[t]{3}{*}{0.000} \\
\hline & Within Groups & 4.735 & 445 & 0.011 & & \\
\hline & Total & 6.881 & 449 & & & \\
\hline \multirow{3}{*}{$\begin{array}{l}50 \text { yard dash } \\
(\text { Speed })\end{array}$} & Between Groups & 154.803 & 4 & 38.701 & \multirow[t]{3}{*}{51.155} & \multirow[t]{3}{*}{0.000} \\
\hline & Within Groups & 336.657 & 445 & 0.757 & & \\
\hline & Total & 491.460 & 449 & & & \\
\hline \multirow{3}{*}{$\begin{array}{l}\text { Pull-ups } \\
\text { (Hands Strength) }\end{array}$} & Between Groups & 949.189 & 4 & 237.297 & \multirow[t]{3}{*}{59.469} & \multirow[t]{3}{*}{0.000} \\
\hline & Within Groups & 1775.675 & 445 & 3.990 & & \\
\hline & Total & 2724.864 & 449 & & & \\
\hline \multirow{3}{*}{$\begin{array}{l}600 \text { Yard Run \& Walk } \\
\text { (Endurance) }\end{array}$} & Between Groups & 6098.172 & 4 & 1524.543 & \multirow[t]{3}{*}{50.376} & \multirow[t]{3}{*}{0.000} \\
\hline & Within Groups & 13467.092 & 445 & 30.263 & & \\
\hline & Total & 19565.264 & 449 & & & \\
\hline
\end{tabular}

The above table shows that the F-ratio was found to be 978.484 which is significant at 0.01 level. It infers that there is significant effect of socio-economic status on Sit-Ups (Legs Strength) of Physical Fitness Parameters.

The above table reflects that the F-ratio was found to be 42.980 which is significant at 0.01 level. It infers that there is significant effect of socio-economic status on Shuttle Run (Agility) of Physical Fitness Parameters.

The above table visualizes that the F-ratio was found to be 50.439 which is significant at 0.01 level. It infers that there is significant effect of socio-economic status on Standing Long Jump (Explosive Strength/Power) of Physical Fitness Parameters.

The above table presents that the F-ratio was found to be 51.155 which is significant at 0.01 level. It infers that there is significant effect of socio-economic status on 50 yard dash (Speed) of Physical Fitness Parameters. 
The above table reveals that the F-ratio was found to be 59.469 which is significant at 0.01 level. It infers that there is significant effect of socio-economic status on Pull-ups (Hands Strength) of Physical Fitness Parameters.

The above table indicates that the F-ratio was found to be 50.376 which is significant at 0.01 level. It infers that there is significant effect of socio-economic status on 600 Yard Run \& Walk (Endurance) of Physical Fitness Parameters.

\section{CONCLUSION}

The hypothesis "There is no significant effect of socio-economic on physical fitness of university level players" is rejected.

\section{Acknowledgments}

The author appreciates all those who participated in the study and helped to facilitate the research process.

Conflict of Interests: The author declared no conflict of interests.

\section{REFERENCES}

Beenackers M.A., Kamphuis C.B.M., Giskes K., Brug J., Kunst A.E., Burdorf A., van Lenthe F.J. Socioeconomic inequalities in occupational, leisure-time, and transport related physical activity among European adults: A systematic review. Int. J. Behav. Nutr. Phys. Act. 2012;9:116.

Gidlow C., Johnston LH., Crone D., Ellis N., James D. A systematic review of the relationship between socio-economic position and physical activity. Health Educ. J. 2016;65:338-367.

Stalsberg R., Pedersen A.V. Effects of socioeconomic status on the physical activity in adolescents: A systematic review of the evidence. Scand. J. Med. Sci. Sports. 2010;20:368-383.

How to cite this article: Ranawat, Y.S \& Rathore, U.S (2017). Effect of Socio-Economic Status on Motor Fitness Parameters. International Journal of Indian Psychology, Vol. 4, (4), DIP:18.01.162/20170404, DOI:10.25215/0404.162 